\title{
PERSPECTIVAS DE SUSTENTABILIDADE E RESPONSABILIDADES NO USO DO BAMBU INDUSTRIALIZADO PARA O DESIGN DE MÓVEIS NO BRASIL
}

\author{
Andre Luis Orthey \\ Universidade Federal do Paraná - UFPR \\ mcorthey@gmail.com \\ Debora Barauna \\ Universidade Federal do Paraná - UFPR \\ debora.barauna1@gmail.com \\ Dalton Luiz Razera \\ Universidade Federal do Paraná - UFPR \\ daltonrazera@ufpr.br
}

Resumo: A utilização do bambu industrializado é pouco conhecida e explorada no Brasil, apesar do longo histórico de uso do bambu pelos países asiáticos e das qualidades e vantagens reconhecidas pela literatura como superiores à madeira. Deste modo, o objetivo deste artigo foi analisar o uso sustentável do bambu industrializado para o design de móveis no Brasil e as respectivas responsabilidades dos designers neste processo. As informações aqui apresentadas foram obtidas por meio de pesquisa bibliográfica e documental. Também foram realizadas entrevistas com designers do setor moveleiro nacional. Os resultados encontrados demonstram que os potenciais do bambu industrializado quanto aos aspectos tecnológicos, econômicos e sociais podem ser devidamente aproveitados se houver maior envolvimento dos designers na utilização deste material, considerando o seu manejo sustentável, o seu potencial produtivo e a capacidade industrial do país na produção de móveis.

Palavras-chave: design de móveis, bambu, bambu industrializado, sustentabilidade.

Abstract: The use of industrial bamboo is little known and exploited in Brazil, despite the historical use of bamboo in the Asian countries and the qualities and advantages recognized by literature as superiors to wood. Thus, the aim of this study was to analyze the sustainable use of industrial bamboo for furniture design in Brazil and the respective responsibilities of designers in this process. The information presented here were obtained through bibliographical and documentary research. Were also carried out interviews with furniture industry designers. The results show that the potential of the industrial bamboo as technological, economic and social aspects can be properly harnessed if there is greater involvement of designers in using this material, considering their sustainable management, 
its productive potential and the country's industrial capacity in furniture production.

Keywords: furniture design, bamboo, industrialized bamboo, sustainability.

\section{INTRODUÇÃO}

Apesar dos estudos acadêmicos realizados no Brasil a respeito da utilização do bambu como uma alternativa de material ambientalmente sustentável, com baixo impacto ambiental negativo e de propriedades superiores à madeira na produção de móveis, sua participação no mercado nacional é inversamente proporcional as suas potencialidades. O que contraria as evidências de uso em países asiáticos. De acordo com Murakami (2007) só na China cerca de 100 empresas no país produzem mais de 10 milhões de $\mathrm{m}^{2}$ de bambu industrializado por ano, com demandas de mercado para o Japão, EUA e Europa.

Os impactos ambientais causados pela produção humana não são apenas especulações, suas consequências são discutidas em âmbito mundial desde a Conferência de Estocolmo em 1972 e comprovadas em estudos de especialistas, como o de Meadows et al. (1973). Neste contexto, no papel de criador de novas necessidades, o design possui responsabilidades que precisam ser discutidas e claramente caracterizadas. Este deve participar ativamente na promoção de ações em que o desenvolvimento econômico, social e ambiental sejam complementares e não antagônicos.

Assim, neste artigo analisou-se o uso sustentável do bambu industrializado para o design de móveis no Brasil e também discutiu-se sobre as responsabilidades dos designers como elementos de aplicação e críticos da utilização de novos materiais e processos. Foram considerados para a análise e discussão os conceitos da sustentabilidade e suas relação aos aspectos sociais, ambientais e econômicos; as características e potencialidades do uso do bambu industrializado no design de móveis; e as percepções de vinte (20) profissionais de design de móveis no país, obtidas por meio de questionamento direcionados a estes, de acordo com suas experiências, conhecimentos e aplicações do material.

\section{SUSTENTABILIDADE E RESPONSABILIDADES DO DESIGN}

Victor Papanek (1971) em Design for the Real World já apresentava a importância do Design em diversos panoramas, do social ao ambiental, do ético ao econômico, do político ao tecnológico e suas diversas relações, demonstrando-o como fundamental para as atividades humanas, principalmente, como ferramenta multidisciplinar de resposta as necessidades do indivíduo e da sociedade.

O autor salientava, porém, sobre a responsabilidade do designer como elemento capacitado para analisar fatos, problemas, sistemas e apresentar uma resposta a estas necessidades, na atenção aos impactos de uma solução e em todos os aspectos de sua interação (PAPANEK, 1971). Tais responsabilidades são novamente apontadas no livro "Green Imperative" (PAPANEK, 1995), onde o autor convoca os designers ao questionamento sobre os resultados de seus projetos nos aspectos ambientais e sociais. 
Desde a década de 70, em virtude da crescente preocupação com o esgotamento e a degradação dos recursos naturais, a questão da sustentabilidade está cada vez mais presente nos diversos universos de interação humana. No campo do desenvolvimento de produtos, a abordagem reparatória das ações e pesquisas realizadas passaram a mudar seu foco para uma visão prevencionista. Investigações foram direcionadas ao campo das inovações, resultando em produtos que tivessem como característica o baixo impacto ambiental durante todo o seu ciclo de vida, a capacidade de reciclagem, propriedades biodegradáveis e a obtenção mediante fontes renováveis (VEZZOLI \& MANZINI, 2006).

No desenvolvimento de produtos, estas abordagens encontram barreiras nos panoramas produtivos que ainda seguem ao pressuposto macroeconômico de: ser rentável no aspecto de valor comercial do objeto (LUGT, P. VAN DER, 2008). Porém, apesar da própria sobrevivência humana atual e futura, depender essencialmente da sustentabilidade na exploração dos complexos sistemas de recursos naturais, o modelo é de produção e consumo insustentável na maioria dos países (SILVA; HEEMANN, 2007). A sustentabilidade ainda é desafiada pelo incontrolado crescimento populacional mundial e pelo aumento do consumo per capita, exigindo cada vez mais dos recursos naturais. Neste cenário três grandes problemas destacam-se no quadro ambiental da humanidade: o esgotamento dos recursos naturais, a degradação dos ecossistemas e a deterioração da saúde humana (LUGT, P. VAN DER, 2008).

Alinhar de forma correta o crescimento econômico com o uso dos recursos naturais, para que se possam desenvolver produtos de forma sustentável, requer atenção para três aspectos distintos e igualmente importantes da sustentabilidade: o social, ambiental e econômico. Deve-se propor uma cultura sustentável de geração de renda (AMÉRICO, 2009).

Desta forma o Design for Environment surge da necessidade de equilíbrio entre as atividades de desenvolver produtos/serviços e a exploração dos recursos naturais, propondo formas sustentáveis de conciliar a competitividade mercadológica de um produto com a qualidade ambiental. É um conceito amplo, que ultrapassa o conhecimento popular de artesanato e reciclagem de materiais, é uma visão mais abrangente que orienta o Design nas questões relevantes para o desenvolvimento mais sustentável de produtos e serviços. O Design for Environment leva o designer a considerar todo ciclo de vida de um produto, ultrapassando os aspectos estéticos, funcionais, ergonômicos, físicos e, principalmente, ambientais envolvidos em todos os momentos de existência do produto, da extração de suas matérias-primas até o momento de descarte após o fim de sua vida útil (PAZMINO, 2007).

Em um panorama de alcance ainda mais abrangente surge o design sustentável. De acordo com Martins e Merino (2011) o design sustentável ou design para a sustentabilidade é aquele que tem como premissa principal a preocupação ambiental em seus projetos de design, procurando utilizar processos e materiais que tenham um reduzido impacto ambiental, sejam economicamente viáveis em todas as etapas de seu ciclo de vida, dando atenção para o descarte e incentivando as possibilidades de reuso. O "[...] Design, alinhado com os conceitos sustentáveis, tem um importante papel no planejamento de um futuro responsável e comprometido com o meio ambiente e com a sociedade" ULLMANN (2005 apud BARAUNA et al., 2006, p. 4).

O impacto ambiental de um produto está presente em todo seu ciclo de existência; da produção, passando pelos processos de distribuição, suas formas de 
utilização e principalmente no descarte após o fim da sua vida útil, sendo que em muitos casos, os impactos ambientais das três fases finais são maiores do que a fase inicial de produção. Em virtude destes fatores o designer tem, além da preocupação e responsabilidade em aplicar tecnologias ecologicamente corretas, a função de promover uma nova forma de pensar os atuais critérios projetuais, transformando-os em bases comparativas para a criação de produtos que atendam aos requisitos sociais, econômicos e ambientais (SILVA; HEEMANN, 2007).

\section{USO DO BAMBU INDUSTRIALIZADO NO DESIGN DE MÓVEIS}

Enquanto a madeira é utilizada em grande escala no Ocidente, como material renovável na fabricação de móveis, nos países asiáticos o bambu é considerado um dos materiais florestais mais importantes na criação de produtos do setor mobiliário. Seu considerável potencial para o desenvolvimento sustentável de produtos está nas excelentes taxas de crescimento e facilidade de processamento. Características essas que o qualifica como um substituto promissor à madeira (LUGT, P. VAN DER, 2008).

A sua taxa de crescimento é $30 \%$ mais rápida do que as espécies de árvores consideradas de rápido crescimento para obtenção da madeira (KOREN, 2010). O bambu é considerado uma das espécies mais altas do reino vegetal e a sua capacidade de produção é renovável, uma vez que após a poda continua a brotar anualmente sem a necessidade de um novo plantio. Além do crescimento rápido, o bambu apresenta um rendimento anual em peso por hectare em cerca de 25 vezes maior do que o verificado nas arvores plantadas para produção de madeira (CASAGRANDE JR. et al., 2003). Aliado a isto está o fato de ser um material de fácil processamento, que pode ser industrial ou manual, onde os recursos tecnológicos envolvidos são mais acessíveis do que os utilizados na produção de móveis feitos de madeira (LUGT, P. VAN DER, 2008).

O bambu pode ser utilizado como uma ferramenta de desenvolvimento social e econômico, ao proporcionar a pequenos produtores rurais a possibilidade de produção e manejo, uma vez que pode ser cultivado em pequenas áreas e ser trabalhado com ferramental simples, proporciona, desta forma, a geração de trabalho e renda (BARELLI, 2009).

Outras características que podem ser acrescentadas às qualidades do bambu são (VOGTLÄNDER et al., 2010):

- As boas propriedades mecânicas;

- Os custos baixos de produção;

- A disponibilidade abundante nos países em desenvolvimento;

- A variedade de uso em diversas outras aplicações na forma de matériaprima e insumos;

- Uma alta taxa de sequestro de dióxido de carbono na sua fase de crescimento;

- O controle da erosão devido às características de forma de sua raiz, melhorando a qualidade de solos degradados, bem como auxiliando na preservação de lençóis freáticos;

- E, sendo por todas estas qualidades, considerado um ótimo recurso de recuperação ambiental.

O déficit atual de madeira plantada, encontrado pelos setores nacionais madeireiros, devido à alta demanda do material e a degradação das florestas nativas, 
promove o bambu industrializado como a alternativa sustentável na produção de móveis e produtos feitos de madeira, além de ser utilizado como matéria-prima para diversas outras aplicações. Na cultura oriental, por exemplo, é utilizado na alimentação, na fabricação de componentes estruturais de engenharia, na produção de chapas, utensílios e também na produção de energia, de forma direta e indireta.

Em comparação as culturas florestais como o Pinus e Eucalipto, onde após atingirem a maioridade são cortados para a produção da madeira, causando um impacto ambiental pela degradação do solo e da fauna existente, o bambu é uma cultura florestal perene e renovável, que proporciona uma proteção ao solo pelas suas características físicas e biológicas (BARELLI, 2009). Além de ser um material leve, flexível, há cerca de 1.300 espécies de bambu existentes. 19 são consideradas prioritárias, possuindo um importante valor social, econômico e ambiental através das diversas aplicações em produtos e insumos (ERENO, 2010).

Os resultados de pesquisas realizadas no Brasil apontam o potencial de uso do bambu industrializado para a produção de móveis: possui uma densidade média em relação à madeira, sua cor natural pode ser alterada através de processos de carbonização, os resíduos podem ser aproveitados para a confecção de outros produtos, possui resistências físicas e mecânicas similares ou superiores a madeira, pode ser trabalhado da mesma forma que as placas feitas de madeira e apresentam um ciclo de produção mais sustentável (CARNEIRO e PEREIRA, 2009). Porém, em termos de aplicação prática, a utilização do bambu no Brasil ainda se limita a sua forma in natura, com características predominantemente artesanais, de baixo apelo estético/funcional e de pouca transformação como matéria-prima, conforme mostra a Figura 1. Isto evidência que a utilização do bambu de forma industrial pelos designers de móveis no país ainda é pouco conhecida ou expressiva.

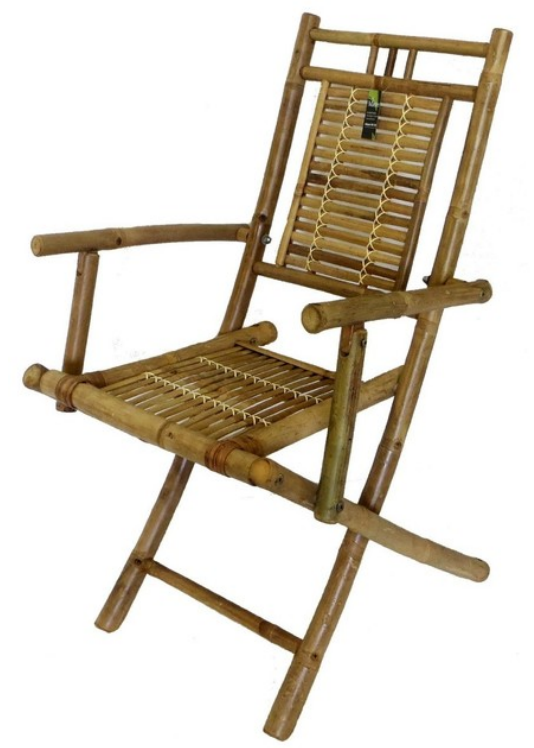

Figura 1 - Cadeira em bambu e com característica artesanal.

Fonte: Master Garden Products (2001).

Ainda não existe no Brasil atualmente, mesmo com a grande disponibilidade ambiental da matéria-prima, uma cadeia produtiva estruturada em termos de produtores e empresas que dominem o cultivo, o manejo e disponibilizem para o mercado a o bambu de forma beneficiada para uso industrial e em larga escala. Isto é um entrave considerável diante de uma perspectiva de futura procura pelo produto. 
Há também a falta no país de fornecedores de mudas de bambu que possam atender à uma grande demanda de produção (BARELLI, 2009).

O único registro identificado pela pesquisa de empresa que operou neste âmbito foi a Oré Brasil, situada na cidade de Campo Alegre - SC e que, após quatro anos de pesquisas e desenvolvimento das etapas de beneficiamento, tratamento, transformação e produção, comercializou no país entre os anos de 2008 a 2011 móveis feitos em bambu industrializado. Em 2011, devido à elevação dos custos do material causado pela reduzido número de produtores, a empresa optou pelo encerramento da utilização do bambu para a produção de móveis, voltando a utilizar a madeira como matéria-prima. De acordo com a empresa há a intenção em retomar o uso bambu industrializado e para isto está investindo em fornecedores próprios para uma maior autonomia, através de incentivos a produtores rurais da região (ORTHEY, 2015).

\section{MÉTODO}

Os dados e informações apresentados no presente artigo forma coletados por meio de pesquisa bibliográfica e documental, realizada em periódicos, dissertações e teses que discutem a linha de pesquisa definida. Primeiramente, foram identificadas as principais bases de dados para a pesquisa e em seguida as palavras-chave para uma busca sistemática do tema. Além destas fontes, foram também foram realizadas entrevistas com designers do setor moveleiro nacional, entre eles designers e arquitetos, responsáveis diretos pela criação e desenvolvimento. Os profissionais envolvidos foram identificados e contatados para participar da pesquisa através do acesso aos seus sites profissionais ou pessoais, sendo as entrevistas realizadas de modo indireto via correio eletrônico na forma de um questionário com seis (6) questões abertas e semi-estruturadas que tratavam da relação entre o conhecimento, a utilização, as justificativas e os possíveis desafios para o uso do bambu industrializado na produção de peças de mobiliário. As questões foram:

1 - Em seus projetos de Design a presença da madeira é uma constante, quais são as razões que o levam a escolher este material para suas peças de mobiliário?

2 - Nestes projetos de Design de móveis, em quais etapas da cadeia produtiva há a sua participação direta e em quais etapas os processos são terceirizados?

3 - Qual o seu conhecimento e experiência a respeito da utilização do bambu industrializado como material de trabalho para a criação de peças de mobiliário?

4 - Quais as justificativas que o levariam a utilizar este material (bambu industrializado) em projetos futuros de móveis, como alternativa à madeira?

5 - Na sua visão e experiência como designer, o que poderia ser feito no Brasil para que o bambu industrializado fosse futuramente visto como uma alternativa viável no projeto de móveis?

6 - Quais seriam as dificuldades/desafios existentes atualmente no Brasil para a utilização da madeira no Design de móveis?

Os requisitos para escolha dos profissionais selecionados para 0 encaminhamento do questionário foram a partir de três aspectos principais: atendimento ao mercado de ponta do setor moveleiro, a experiência notoriamente reconhecida pelos pares no Design de móveis e a experiência de uso da madeira em suas coleções de mobiliário. A amostra desses profissionais contatados compreendeu a vinte (20) profissionais brasileiros, sendo três (3) do sexo feminino e dezessete (17) do sexo masculino, entre as idades de 25 a 45 anos e média de 15 anos de experiência no 
mercado, atuantes nas principais regiões consumidoras do país, entre elas, principalmente a região sudeste.

\section{RESULTADOS E DISCUSSÃO}

O potencial do bambu industrializado em termos tecnológicos, ambientais e sociais justificam esforços em investimentos como um produto economicamente viável na produção de móveis no país. Suas características mecânicas superiores a madeira, sua sustentabilidade ambiental de produção e plantio, bem como as possibilidades de participação e desenvolvimento da agricultura familiar, são diferenciais importantes que podem ser devidamente potencializados pelo design de móveis para promoção deste material.

As iniciativas existentes atualmente quanto a utilização do bambu são apenas pontuais e envolvem a aplicação do material em pequenos objetos de características artesanais, não há no país uma cadeia de produção completa na sua forma industrializada, que compreenda desde o plantio do bambu até a sua comercialização ao consumidor final e principalmente empresas moveleira que se disponham a trabalhar com este material na mesma escala em que foi produzido na empresa Oré Brasil, atuando em duas linhas principais de produção: a linha de beneficiamento do bambu e a linha de produção dos móveis.

O incentivo ao uso do bambu industrializado para o design de móveis não implica na substituição da madeira pelo bambu, mas visa complementar e ampliar qualitativamente as possibilidades de uso deste material pelas empresas e designers do país, contribuindo desta forma para o uso sustentável dos recursos florestais no país.

Quanto ao objetivo de mostrar a percepção dos profissionais envolvidos no design de móveis no país sobre o uso do bambu em sua forma industrializada, as respostas dos especialistas sobre suas possíveis experiências e conhecimentos em relação ao uso do bambu industrializado no Design de móveis foram assim distribuídas em termos proporcionais:

- $5 \%$ apenas comercializam o produto já pronto;

- $5 \%$ conhecem e já testaram o material (bambu);

- 50\% conhecem o material, mas desconhece a aplicação do mesmo em móveis;

- $40 \%$ não conhecem as características e propriedades do material (bambu industrializado).

Com as respostas percebeu-se que a metade dos entrevistados afirmaram apenas conhecer o bambu industrializado, mas desconheciam e não possuíam qualquer experiência na sua aplicação em Design de móveis. Outra parte, em sua maioria, não conheciam as características e propriedades do material em sua forma industrializada. Apenas um profissional comercializava no país móveis importados da China. Do total de entrevistados somente dois designers afirmaram conhecer a coleção de móveis em bambu industrializado produzida pela Oré Brasil, Figura 2, criada pelo designer Paulo Foggiato. 


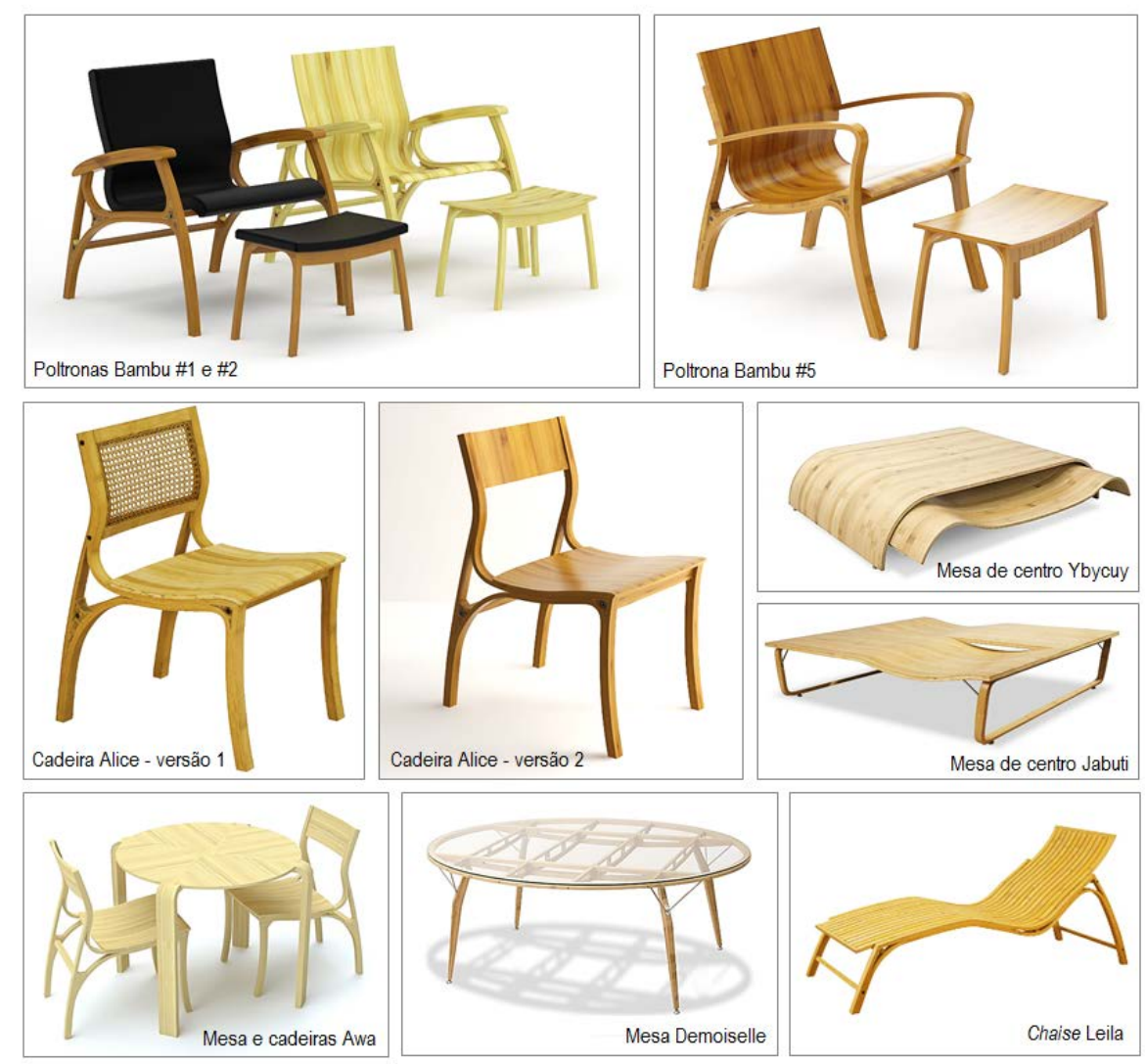

Figura 2 - Coleção da Oré Brasil de móveis em bambu industrializado.

Fonte: Adaptado de Foggiato (2015)

Entre todos os entrevistados apenas um tinha a experiência de trabalhar com o bambu industrializado, em parceria com uma empresa que importava da China o material pronto, na forma de chapas, para montagem em tampos e prateleiras. Assim, este aproveitou a oportunidade para realizar alguns testes com 0 bambu industrializado em protótipos de estruturas de mesas e luminárias.

A pesquisa realizada abordou e questionou ainda sobre à participação dos designers nos processos de criação, prototipagem e produção dos móveis feitos em madeira, material correspondente ao bambu, em termos de aspectos, características e propriedades. A distribuição das respostas em termos de participação nos processos de criação e produção de móveis em madeira ficou assim distribuída percentualmente:

- $30 \%$ participam em todas as etapas de produção;

- $5 \%$ participam na criação e orientação da produção;

- $5 \%$ participam na criação e na prototipagem;

- $35 \%$ participam na criação e apenas orientam a prototipagem;

- $20 \%$ participam apenas na criação;

- $5 \%$ apenas comercializam.

Pode-se constatar que em termos de envolvimento nos processos citados que a grande maioria atua apenas na criação dos móveis, sem participar nos processos de produção das peças. Estes estendem esta atuação nesse processo somente quando requisitados na orientação sobre o desenvolvimento dos protótipos. Trinta por cento (30\%) dos participantes atuam em todos os processos, desde a criação até as etapas de produção das peças. Com isso assumem maior influência e responsabilidade do 
processo. No entanto, um total de sessenta e cinco por cento (65\%) dos especialistas não se envolvem com as etapas de produção dos móveis.

Quando questionados sobre quais seriam as justificativas para utilizarem o bambu industrializado em suas próprias coleções e sobre o que poderia ser feito para incentivar o uso deste material como uma alternativa viável para o Design de móveis no Brasil, os seguintes aspectos foram apontados:

- Maior divulgação aos designers sobre as possibilidades técnicas e aplicações do material, esclarecendo sobre as vantagens de uso do bambu industrializado.

- Maior divulgação às empresas fabricantes de móveis sobre características e versatilidade de uso.

- Maior disponibilidade no mercado nacional, proporcionando redução em seu custo, e tornando-o competitivo em relação aos demais materiais.

- Em primeiro lugar aprimorar e desenvolver o plantio e a oferta no país e em segundo lugar mudar a visão do mercado consumidor final sobre as qualidades do bambu, justificando seu custo-benefício.

- Lançamento de mais produtos de Design com qualidade e impacto comercial, que utilizem o bambu industrializado para motivar e orientar o mercado consumidor.

- Desenvolvimento por parte da indústria de máquinas, equipamentos e ferramentais bem como mão de obra especializada, proporcionando ao Design explorar o uso do material e oferecer ao mercado mais peças de qualidade, aumentando as vendas e, consequentemente, o custo de produção dos móveis feitos com bambu industrializado.

As respostas obtidas pelo estudo a partir das entrevistas sobre as características do bambu, demonstram que os profissionais possuem um relativo conhecimento sobre as qualidades e características mecânicas, estéticas e ambientais do material. Porém este conhecimento não vai além da forma in natura, fortemente ligada no país a produtos de características artesanais e de baixo valor agregado. De acordo com os profissionais entrevistados é preciso uma maior divulgação sobre as possibilidades de uso do bambu na sua forma industrializada.

Tais respostas mostram ao mesmo tempo que faltam iniciativas por parte dos designers na pesquisa e na busca de informações já existentes no país a respeito das aplicações do bambu industrializado. Uma mudança desta realidade pode ser alcançada com a participação mais ativa dos designers no desenvolvimento de novas possibilidades para este material, justificando o papel do Design no questionamento e na busca de novas soluções que contemplem as questões ambientais e sociais, e não apenas as econômicas e tecnológicas.

\section{CONCLUSÃO}

As perspectivas do bambu em termos de participação de mercado, comparativamente aos principais tipos de madeiras utilizadas para fabricação de móveis, são promissoras e de grande potencial, desde que sejam feitos investimentos para superação dos obstáculos encontrados em sua base de produção, onde o domínio de tecnologias e o número de produtores/fornecedores de matéria-prima é quase inexistente. Este aspecto deve ser considerado na possibilidade futura de uso do bambu industrializado, pois as plantações naturais de bambu, adequadas para o setor moveleiro, não suportariam a demanda comercialmente exigidas. 
Em contrapartida, os aspectos positivos do bambu como matéria-prima para o setor de móveis são fatores motivadores de grande peso para os investimentos necessários a superação destas dificuldades iniciais. Entre estes aspectos está a alta capacidade de crescimento e produção do bambu em relação à madeira, as boas qualidades físicas e propriedades mecânicas, a capacidade de recuperação ambiental de solos degradados e erodidos, a possibilidade social e econômica da participação de pequenos produtores rurais no processo de plantio e produção das matérias-primas, devido ao fácil manejo, ao ferramental mais simples de produção e a pequena necessidade de área cultivada, além de ser um ótimo sequestrador de dióxido de carbono.

Se forem combinados os resultados já obtidos nos centros de pesquisas, com os processos já desenvolvidos pela iniciativa privada e uma participação mais ativa dos designers, poderá com grandes chances de sucesso apresentar-se o bambu industrializado com uma alternativa sustentável ao uso da madeira, considerando-se suas características e qualidades já abordadas e comprovadas em outras pesquisas.

As discussões e ações propostas pelo presente estudo podem ser complementadas por futuras pesquisas sobre a cadeia produtiva do bambu industrializado, resgatando por exemplo as ações promovidas pelos centros de pesquisa existentes no país e também os resultados obtidos pelas pesquisas contempladas nos editais já lançados, que tiveram como objetivos instituir e estruturar a cadeia produtiva do bambu no país.

\section{REFERÊNCIAS}

AMÉRICO, L. Eco-Design e a utilização de materiais alternativos renováveis : o Bambu e sua inter-relação com o design. Anais do $2^{\circ}$ Simpósio Brasileiro de Design Sustentável (II SBDS), p. 9, 2009.

BARAUNA, Debora, SILVEIRA, Juliana, BASTIANELLO, Silvana Fehn. A interferência do profissional de design na produção artesanal In: $7^{\circ}$ Congresso Brasileiro de Pesquisa e Desenvolvimento em Design, 2006, Curitiba/PR. Anais do P\&D em Design 2006. Porto Alegre/RS: AEND Brasil, 2006b

BARELLI, B. G. P. Design para a sustentabilidade: Modelo de cadeia produtiva do bambu laminado colado (BLC) e seus produtos, 2009. Unesp.

BERALDO, A. L.; RIVERO, L. A. Bambu laminado colado (BLC). Floresta e Ambiente, v. 10, n. 2, p. 36-46, 2003.

CARNEIRO, R. R.; PEREIRA, M. A. DOS R. Desenvolvimento de produtos em bambu laminado colado e a transferência deste conhecimento ao assentamento rural horto aimorés. Settlement horto. XXI Congresso de Iniciação Científica da UNESP. Anais... p.1459-1462, 2009. São José do Rio Preto - SP: UNESP.

CASAGRANDE JR., E. F.; UMEZAWA, H. A.; TAKEDA, J. Arranjo Produtivo Local Sustentável : Estudo de caso para o uso do potencial do bambu na geração de emprego e renda no Paraná. , p. 1-8, 2003.

ERENO, D. Anatomia flexível. Pesquisa FAPESP, , n. 175, p. 74-77, Sep. 2010. São Paulo. Disponível em: <http://revistapesquisa.fapesp.br/wp-content/uploads/2012/07/074077-175.pdf>. 
FOGGIATO, P. Entrevista concedida pelo designer. 2014.

KOREN, G. New Bamboo Product for the Global Market. 2010.

LUGT, P. VAN DER. Design interventions for stimulating bamboo commercialization Dutch design meets bamboo as a replicable model. ,2008. Disponível em:

$<$ http://www.narcis.nl/publication/RecordID/oai:tudelft.nl:uuid:6ee4497f-9a2c-4d40ba89-d869e2d75435>. Acesso em: 16/3/2013.

MARTINS, R. F. F.; MERINO, E. A. D. A gestão de design como estratégia organizacional. 2. ed. Londrina : Eduel; Rio de Janeiro : Rio Books, 2011.

MEADOWS, D. H.; MEADOWS, D.L.; RANDERS, J.; BEHRENS III, W. W. Limites do crescimento, SP: Editora Perspectiva AS, 1973.

MURAKAMI, C.H. O bambu: matéria-prima do futuro. Boletim Florestal, São Paulo, v.1, n.6, p.5, 2007

ORTHEY, A. L. Uso do bambu industrializado no Brasil e sua aplicação no design de móveis: estudo de caso da empresa Oré Brasil. 2015. Dissertação - UFPR - PPGDesign.

PAPANEK, V. Design for the real world. New York, 1971.

PAPANEK, V. The Green Imperative: Ecology and Ethics in Design and Architeture. Thames \& Hudson, New York, 1995.

PAZMINO, A. V. Uma reflexão sobre Design Social , Eco Design e Design Sustentável. I Simpósio Brasileiro de Design Sustentável. Anais... p.1-10, 2007. Curitiba.

RIVERO, L. A. Laminado colado e contraplacado de bambu, 2003. UNIVERSIDADE ESTADUAL DE CAMPINAS.

SILVA, J. S. G. DA; HEEMANN, A. Eco-concepção: Design, ética e sustentabilidade ambiental. I Encontro de Sustentabilidade em Projeto do Vale do Itajaí. Anais... p.109112, 2007. Itajaí.

SZÜCS, C. A.; SOARES, M.; OLIVEIRA, R. C. DE; PORATH, J. F. Bambu laminado colado para fabricação de movéis em Santa Catarina. Anais do II Seminário Nacional do Bambu: Anais... p.143 - 154, 2011. Rio Branco.

VEZZOLI, C.; MANZINI, E. Design for Sustainable Consumption. Changes to Sustainable Consumption. Anais... p.167-197, 2006. Copenhagen.

VOGTLÄNDER, J.; LUGT, PABLO VAN DER; BREZET, H. The sustainability of bamboo products for local and Western European applications. LCAs and land-use. Journal of Cleaner Production, v. 18, n. 13, p. 1260-1269, 2010. Elsevier Ltd. Disponível em: <http://linkinghub.elsevier.com/retrieve/pii/S0959652610001666>. Acesso em: 13/3/2013. 